\title{
Comparison of sediment transport formulae with monthly 2DH simulation on a sandy beach and on a beach with non- eroded sea bed zone
}

\author{
Philippe Larroudé, LEGI BP 5338041 Grenoble, France, larroude@hmg.inpg.fr \\ Mehdi Doua, LEGI BP 5338041 Grenoble, France, dimehrepier@gmail.com
}

\begin{abstract}
This paper discusses the abilities of numerical models to predict the morphodynamics over loose and rigid beds. In the first part the sediment transport model is presented which solves the bed evolution equation in conjunction with sediment transport formulas. The flow field and the water depth are calculated using the depth-averaged hydrodynamic model TELEMAC-2D developed by Électricité de France
\end{abstract}

Keywords: large scale features, nearshore region, morphological evolution, Sediment transport, numerical simulation 2DH and Multi1DH model

\section{Introduction}

The work consisted in setting up the methodology of calculation (De Vriend and Stive (1987)). The principle is to make an external coupling of three codes. This coupling consists in enchained Artemis for swells, Telemac2d for the currents and Sisyphe for the morphodynamic evolution (Hervouet J.M .,2007). The basic principle of this external coupling is to make this loop on the codes with a step of morpho-dynamic time depending essentially on weather conditions and on the environment hydrodynamics of the studied beach. These models were used in the framework of a simulated meteorological cycle describing the seasonal evolution of hydrodynamic factors.

This paper discusses the abilities of numerical models to predict the morphodynamics over sandy and rigid beds. In the first part the sediment transport model is presented which solves the bed evolution equation in conjunction with sediment transport formulas. The flow field and the water depth are calculated using the depth-averaged hydrodynamic model TELEMAC-2D and simplified model called Multi1dh. This model was already used and tested in Camenen and Larroudé, (2003b).

The objectives which we want to reach during this program are multiple. First, we are going to set up a procedure of linking of three codes to be able to simulate realistic or idealized climates. This procedure is validated from the point of view of the hydrodynamics and 
morpho-dynamic evolution (Larroudé, 2008). Then this technique of simulation will be use to compare and studied the contribution of the various formulae of sedimentary transport (as in Camenen and Larroudé (2003) on the site of Sète (Certain and Barusseau (2006)) and the effects of roughness and zone of non eroded sea bed on the site of Lacapte (south east of France).

\section{The study Areas}

Site 1 : The "Plage de la Corniche", located about on Sète lido Mediterranean sea, France, was selected as the study area (Fig. 1). Located in a microtidal, swell-dominated coastal environment, the "Plage de la Corniche" is a linear beach of about $2.5 \mathrm{~km}$ length. The mean near shore bed slope is 0.04 , while the median grain size in the surf zone is $0.25 \mathrm{~mm}$.

The mean significant offshore wave height is about $1.5 \mathrm{~m}$ increasing to 3-6 $\mathrm{m}$ during storms, while the predominant wave direction is from SSE with occasional SE swells. There is no significant seasonal variation in the offshore wave climate.

Certain and Barusseau (2006) show that the morphodynamic evolution of offshore bars in a microtidal environment and bimodal moderate wave regime follows two different conceptual models, the main one being a seasonal pattern in line with the observed cycle of hydrodynamic conditions.

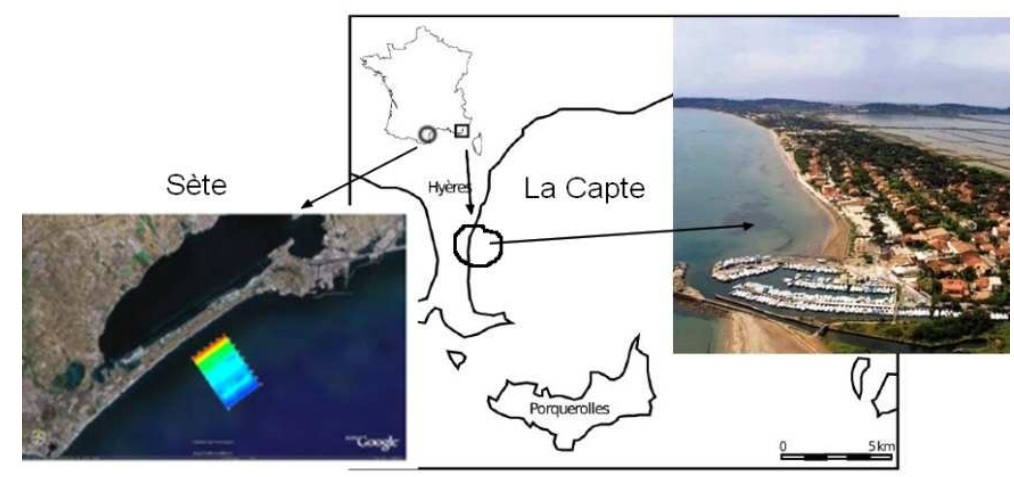

Fig. 1: Localisation of the "plage de la Corniche" at Sète in Mediterranean Sea and of the beach of La Capte (Hyères).

Site 2: The second site is located close the tombolo of Giens (in the south east of France) and is named "Plage de La Capte" (Hyères) (Fig.1). The two particularities on this sandy beach are the non erodible sea bed in several zone and the presence of seagrass: the posidonia oceanica. Located in a microtidal, swell-dominated coastal environment, Plage de La Capte is a linear beach of about $1.5 \mathrm{~km}$ length. The mean near shore bed slope is weak until 4 meter of water depth (200 meters for the shore line) at this distance begins the posidonia. The median grain size in the surf zone is $0.2 \mathrm{~mm}$.

\section{The model and the methodology}

The sedimentary evolution is modelled under the action of the oblique incident waves and is coupled with different numerical tools dedicated to the other process involved in the near shore zone. We can mention the following modules: 
The wave module takes into account the surge energy dissipation (hyperbolic equation of extended Berkhoff), (LNHE, Artemis, 2002). The Artemis code (Agitation and Refraction with Telemac2d on a Mlld Slope) solves the Berkhoff equation taken from Navier-Stokes equations with some other hypotheses (little camber of the surface wave, little slope...).

The main results are, for every node of the mesh, the height, the phase and the incidence of the waves. Artemis can take into account the reflection and the refraction of waves on an obstacle, the bottom friction and the breakers. One of the difficulties with Artemis is that a fine mesh must be used to have good results whereas Telemac2d does not need such a fine mesh.

The hydrodynamic module calculates currents induced by means of the surge of the waves, from the concept of radiation constraints obtained according to the module of waves, (LNHE, Telemac2d, 2002). Telemac2d is designed to simulate the free surface flow of water in coastal areas or in rivers. This code solves Barré Saint-Venant equations taken from NavierStokes equations vertically averaged.

Then, the main results are, for every node of the mesh, the water depth and the velocity averaged over the depth. Telemac2d is able to represent the following physical phenomena: propagation of long periodic waves, including non-linear effects, wetting and drying of intertidal zone, bed friction, turbulence,...

The sedimentary module integrating the combined actions of the waves and the wave currents (2D or 3D) on the transport of sediment, (LNHE, Sisyphe, 2002),

The Sisyphe code solves the bottom evolution equation which expresses the conservation of matter by directly using a current field result file given by Telemac2d. (Fig. 2)

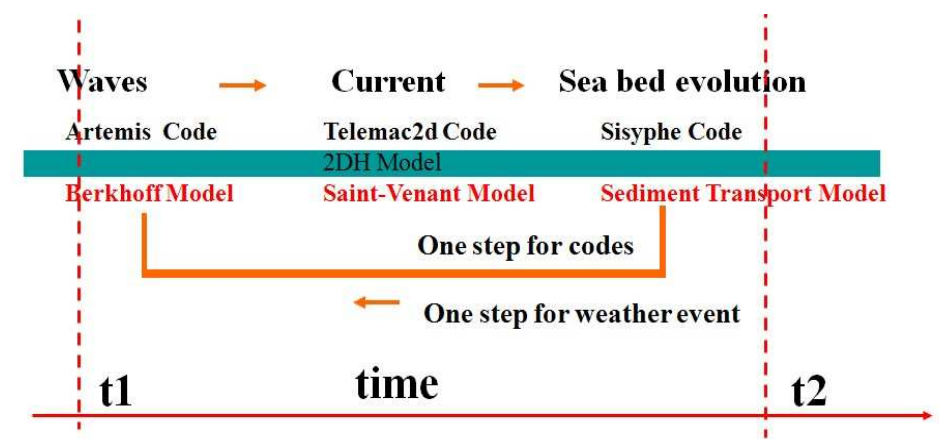

Fig. 2: Diagram of the model ATS (Artemis-Telemac-Sisyphe) loop over one weather event time step (between $\mathrm{t} 1$ and $\mathrm{t} 2$ used for our simulations.

Several of the most currently empirical or semi-empirical formulas are already integrated in Sisyphe. In this paper we show only the simulations with the Bijker formulas. The main results are, for every node of the mesh, the bottom evolution and the solid transport. The equations of the three modules are detailed in Hervouet (2007).

A hydrodynamic simplified model (called Multi1DH) uses the following assumptions: a random wave approach, in a $1 \mathrm{DH}$ (cross-shore) direction. An offshore wave model (shoaling + bottom friction + wave asymmetry) is used with the break point estimation. The waves in the surf zone are modeled with the classic model of Svendsen (1984) with an undertow model (roller effect, Svendsen, 1984, Dally et al. 1984). The long shore current model is the 
Longuet-Higgins's model (1970). The model is included in the Sysiphe code to calculate the sea bed evolution with several sediment transports formulas.

\section{Results and discussions}

We set up a procedure to use the coupled codes Artemis-Telemac2d-Sisyphe and more particularly we improved the treatment of the boundary conditions in order to be able to work on fields of calculations close to the coastal zone and equivalents in dimension for the three codes. The wave module grid is equal to the flow and morphodynamic grid. The waves are incidents on both the lateral and seaward boundaries of the grid. The lateral boundaries of the flow model are defined as zero water levels.

The morphological evolution in the near shore region, including its large-scale features, was first investigated using a combination of a commercial 2DH model (Camenen and Larroudé, $2003,2003 b$ ). Simulation of the wave-driven currents was carried out with Telemac, a finite elements model, and the Sisyphe sand transport module served to compute sediment transport rates and bed evolution. This methodology of morphodynamic modelisation for sandy beaches was already improved in terms of mesh, time step and convergence in Camenen (2002), Larroudé and Camenen (2004) and in Falquès et al. (2008) and Larroudé (2008).

In this paper we focus on the month of December 2008 and February 2009 for the validation and the first test of the different sediment transport formulas. During this month we had two similar storms in term of significant wave height, period but in December the outer bar move offshore and during the storm of February this outer bar move onshore (see Fig. $3 a$ and $3 b$ ).

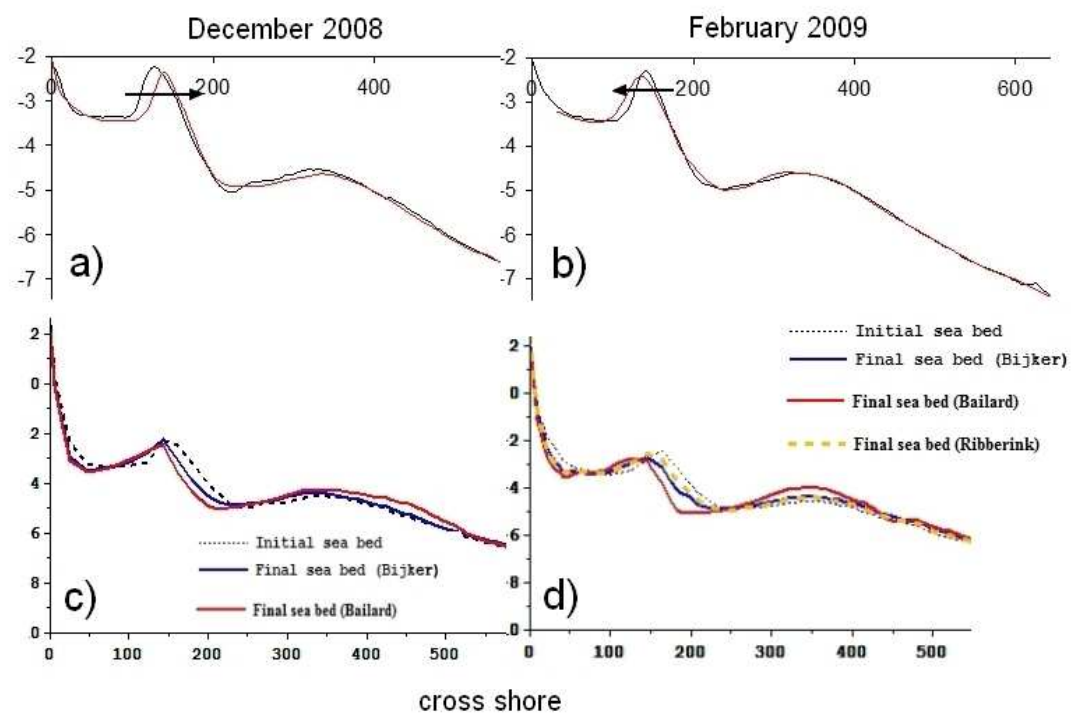

Fig. 3: Morphodynamic evolution in December 2008 a) measured in situ (initial bathymetry in black) and c) with simplified model Multi1DH and several sediment transport formulas and in February 2009 b) measured in situ (initial bathymetry in black) and d) with simplified model Multi1DH and several sediment transport formulas

In the case of February, the Multi1dh model reproduces very well the onshore migration of the bar with all the sediment transport formulas (Fig. 3b,3d). On the opposite, the off shore migration is not so well simulated but the result seems to be acceptable (Fig. 3a,3c). For the 2DH model ATS, in these cases of cross shore migration of the sandy structure, the modelisation of the cross shore current called undertow is missing. The results for the both 
storm are not well representatives (Fig. 4)

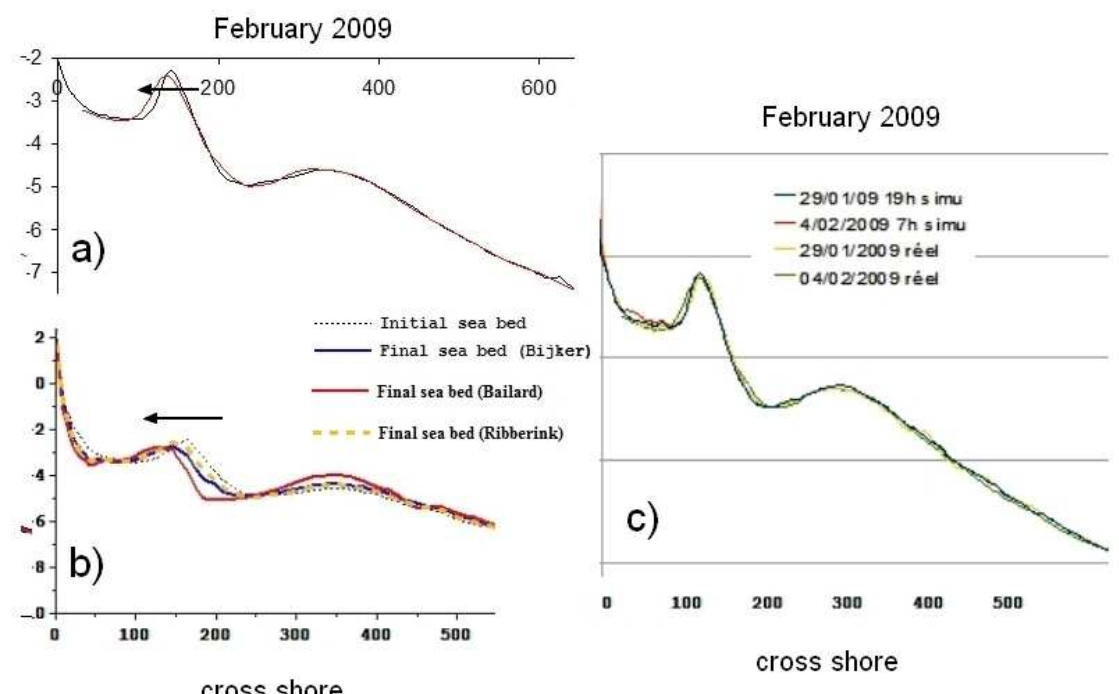

Fig. 4: Morphodynamic evolution from the 290109 to the 040209 , a) measured in situ (initial bathymetry in black), b) with simplified model Multi1DH and several sediment transport formulas and c) with the 2DH model ATS.

The site of "Plage de La Capte" has two main interests in terms of modeling. First how to improve the code for sediment transport must be treated as zones of rocky plates. Currently the code is able to taking into account non-erodible areas but only simple geometric shapes. The first numerical tests show that the approach of non-erodible bottom works but is not yet possible to simulate the exact shape of the rocky bottom that we have on the La Capte beach.

Secondly, there is on the site many seagrass meadow. They will play an important role in the attenuation of swells and currents. From the perspective of modeling we will try to take into account the seagrass in creating zones of different roughness on the entire area scanned. Our initial simulations show the importance of roughness parameter on the velocities alongshore and cross-shore (Fig. 5). We can see the difference between the both velocity component in the north zone with the very low Strickler coefficient (Fig 5.c) in comparison with the two other tests (Fig 5.a and b). 


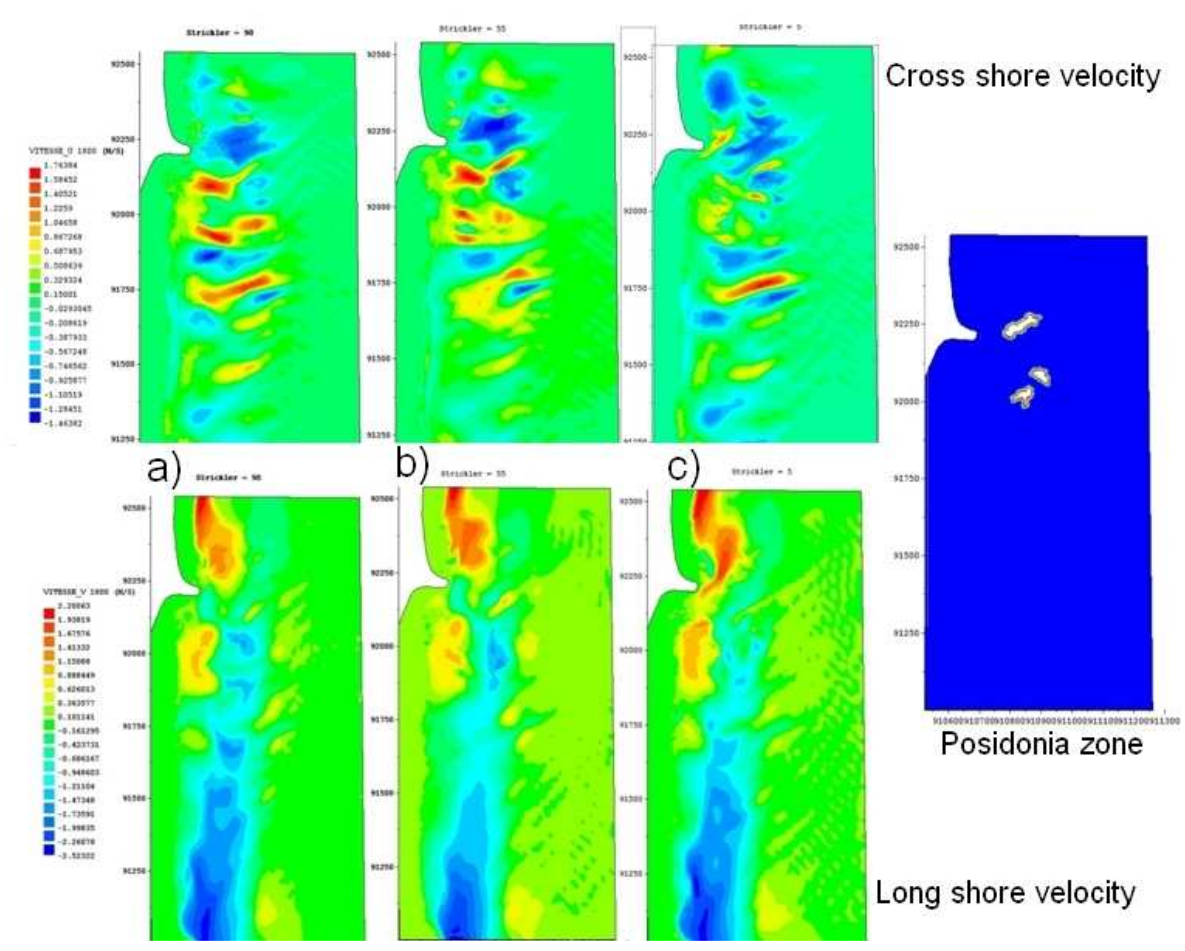

Fig. 5: Velocity fields for different coefficients of friction for better representation of Posidonia at La Capte in Hyères. Strickler is equal to 90 (a) - 50 (b) and 5 (c).

The work still to do on this site is to improve the code to be non-erodible areas and realistic use in situ data transmission to highlight a size of the numerical roughness to simulate the size and thickness seagrass meadow.

\section{Conclusions}

We used a $2 \mathrm{DH}$ morphodynamic model to simulate the evolution of linear sandy beaches with major implications to find vulnerability to storm event. We have calibrated our numerical methodology of simulation against in situ measurements. The first results are good in terms of comparison with in-situ data regarding the hydrodynamic and morphodynamic parameters. Now, we have had to create a lot of scenarios on wave classes, storm occurrences ...

We have had to simulate all these configurations to identify the sensitivity of rising-apexwaning of the storm. Our methodology of simulation and the complementarily of the both model allows us to test all the configuration of storm to understand the results issued from the in-situ data. On the site of La Capte, the in situ measurement of the roughness and of the wave height and velocity offshore-onshore located will allows us to calibrate our methodology of simulation with rocky and posidonia zone.

\section{References}

Camenen, B., 2002, Modélisation numérique du transport sédimentaire sur une plage sableuse. PhD thesis, Université Joseph Fourier, Grenoble, 298 p. 
Camenen, B. and Larroudé, Ph., 2003, Comparison of sediment transport formulae for a coastal environment, Journal of Coastal Engineering, 48, pp. 111-132.

Camenen, B. and Larroudé, Ph., 2003b, Un modèle morphologique côtier pour la création de barres rythmiques, Revue française de génie civil, Génie côtier, vol. 7, pp. 1099-1116, 2003.

Certain, R., 2002, Morphodynamique d'une côte sableuse microtidale à barres : le golfe du Lion (Languedoc-Roussillon). PhD Thesis, University of Perpignan, 199 pp.

Certain, R. and Barusseau J.P., 2006, Conceptual modelling of straight sand bars morphodynamics for a microtidal beach (Gulf of Lions, France), ICCE 2006, San Diego.

Dally W.R., Dean R.G., and Dalrymple R.A. , 1984. A model for breaker decay on beaches. In 19th Coastal Eng. Conf. Proc., pages 82-88. ASCE.

De Vriend, H.J., 1987, 2DH Mathematical Modelling of Morphological Evolutions in Shallow Water, Coastal Engineering ,11, pages 1-27

De Vriend, H.J. and Stive M.J.F., 1987, Quasi-3D Modelling of Nearshore Currents, Coastal Engineering ,11, pp. 565-601.

Falques A., Dodd N., Garnier R., Ribas F., MacHardy L.C., Sancho F., Larroudé Ph. and Calvete D. , 2008, Rhythmic surf zone bars and morphodynamic self-organization, Coastal Engineering 55, pp 622-641.

Hervouet, J.M., Hydrodynamics of Free Surface Flows: Modelling With the Finite Element Method, 2007, John Wiley \& Sons, 360p.

Larroudé Ph., 2008, Methodology of seasonal morphological modelisation for nourishment strategies on a Mediterranean beach, Marine Pollution Bulletin 57, pp 45-52.

Larroudé, Ph., Camenen, B., 2004, 2DH and multi1DH morphological model for medium term evolution of large scale features and nourishment in the nearshore region: application to TrucVert and Corniche beach (France) and la Barrosa beach (Spain). 29th International Conference on Coastal Engineering. ASCE, Lisbon.

Longuet Higgins M..S., 1970, Longshore currents generated by obliquely incidentsea waves, Journal of geophysical research, vol 75, n33, pp. 60778-60801

Smit M.W.J., Reniers A.J.H.M., Ruessink B.G., Roelvink J.A., 2008, The morphological response of a nearshore double sandbar system to constant wave forcing, Coastal Engineering 55, pp. 761-770.

Svendsen I.A. 1984, Mass flux and undertow in the surf zone, Coastal . Eng. , 8, pp. 347365.

\section{Acknowledgements}

This work has been supported by French Research National Agency (ANR) through the Vulnerability Milieu and Climate program (project VULSACO, $\mathrm{n}^{\circ}$ ANR-06-VMC-009) and RELIEF MICROLIT. We highly appreciate the constructive discussions with D. Idier, (BRGM, Orléans, France), Raphaël Certain and Nicolas Robin from the University of Perpignan. 